\title{
The Piezo-Electric Loud-Speaker
}

$\mathrm{M}$ ODERN broadcasting receivers tend to give an undue response to the lower audio frequencies, and in the majority of cases the range is limited to frequencies below 5,000 eycles per second. This is partly due to the fact that the lower frequencies, which at one time were not reproduced very well, have now become attractive as lending power and tone to the reproduction, but it is also due to the demand for increased range in distant reception, for which purpose a high selectivity is required, a virtue which is most easily attained by reducing or eliminating the higher frequencies. Compensation for this latter deficiency can be obtained to some extent by using tone-correcting arrangements in the audiofrequency stages of the receiver, but the effect of these in the sound reproduction is rather handicapped by the poor response of the moving-coil type of loudspeaker to the higher audio-frequencies.

A solution of this difficulty is now in view in the form of the piezo-electric loud-speaker, an investigation of which has been described in a paper by Stuart Ballantine, of the Boonton Research Corporation, U.S.A., published in the Proceedings of the Institute of Radio Engineers of October 1933. The loud-speaker employed in these measurements was of the horn type and was driven by a piezo-electrically active diaphragm built up of crystals of Rochelle salt (sodium potassium tartrate), prepared by the Brush Development Company of Cleveland, Ohio. The diaphragm is formed of four pairs of crystal plates, the plates of each pair being so cut that they move in opposite directions under the influence of an electromotive force. The opposite faces of such a pair of plates are cemented together, and the combination, when clamped along one edge, tends to twist on the application of a potential difference to its foil electrodes. Four such units are cemented together to form a flat square diaphragm, which is clamped around its periphery, so that in use the centre portion or junction of the four units vibrates normally to the plane of the assembly, and in synchronism with the audio frequency electromotive force applied to the metal foil electrodes.

The characteristic of this type of loud-speaker, that is, the relation of output sound pressure to frequency, can be controlled to some extent by the electrical circuit in which it is used and also by the resonant frequency of the crystal diaphragm, which depends upon its dimensions. In an example illus. trated in the above paper, the sound pressure rises fairly uniformly with frequency from about 1,000 cycles per second to the resonant value at 8,000 cycles per second. This characteristic may be partially levelled off by suitably connecting it to an electrical circuit; and in a second case in which the loudspeaker was fed through a transformer in series with an inductance, the sound output, after increasing rapidly between frequencies of 1,000 and 2,000 cycles per second, remained sensibly uniform for higher frequencies up to 10,000 eycles per second. This type of response immediately suggests the possibilities of a combination of a piezo-electric loud-speaker with one of the moving-coil type, in which the output is moderately constant for low frequencies but falls rapidly above the cut-off frequency. Ballantine describes such a combination using a moving-coil loud-speaker which has been designed for uniform reproduction up to 3,000 cycles per second, with a rapidly falling response above that frequency. The combined output is shown to be approximately uniform at all frequencies between 60 and 9,000 cycles per second. Such dual arrangements have the advantage that the response can be limited to that of the low-frequency member of the pair if considerations of hoise or transmission interference make this desirable.

The piezo-electric loud-speaker also forms the subject of an article in the Wireless World of January 5, in which the development in Great Britain, by the Rothermel Corporation Ltd., is briefly described and illustrated. In this case the crystal unit is built up of four laminations, approximately $2 \frac{1}{2} \mathrm{in}$. square, the total thickness being $\frac{1}{4}$ in. Three of the corners of this assembly are clamped between rubber blocks, and the vibration of the fourth corner is used to drive the cone diaphragm. The equivalent capacity of this unit is of the order of $0.03 \mathrm{mfd}$., and it is suitable for use in conjunction with an ordinary moving-coil output transformer. The efficiency of the unit appears to be very good, particularly in the frequency range 2,000-8,000 cycles per second; while in combination with a standard type of permanent moving-coil loud-speaker the quality of reproduction is claimed to be superior to that hitherto obtained with commercial dual moving-coil units.

\section{Larval Crabs from Japan*}

$\mathrm{D}^{\mathrm{n}}$ R. HIROAKI AIKAWA has recently supplemented his first paper on the newly-hatched crab zoeas of Japan (1929) with one on the intermediate (later zoeal) stages between the first zoea and the megalopa. Crab zoeas of all kinds are very common in the Japanese plankton, but few of them have been traced to the adults, and the author has devised a distinctly helpful scheme for placing them in groups characterised by definite features. Recent research by other workers has shown that there are several larval characters by means of which the

\footnotetext{
* Records of Oceanographic Works in Japan, 5, No. 2, June 1933. "On Larval Forms of Some Brachyura".
} Indeterminable Zoeas", by Hiroaki Aikawa. various natural divisions can be recognised; the Oxyrhyncha can be divided from the Brachyrhyncha and many of the families and genera can be identified, whilst by rearing the individuals several species are now known throughout the whole life-history. The Dromiacea always stand apart and should certainly be separated from the Brachyura.

The most important features which can be used in classification are the number of spines on the carapace, the form of the antennæe and the number and position of the spines on the telson. Dr. Aikawa uses the position on the body of the main chromatophores, but these are no good in long-preserved material, Besides elaborating the classification of 